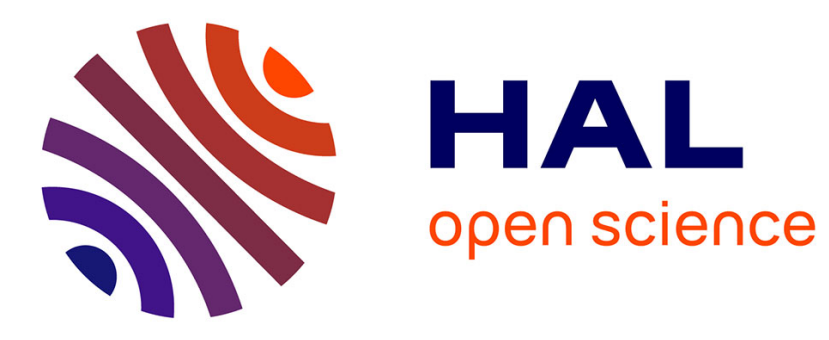

\title{
Direct electrochemical oxidation of a pesticide, 2,4-dichlorophenoxyacetic acid, at the surface of a graphite felt electrode: Biodegradability improvement
}

Jean-Marie Fontmorin, Florence Fourcade, Florence Geneste, Isabelle Soutrel, Didier Floner, Abdeltif Amrane

\section{To cite this version:}

Jean-Marie Fontmorin, Florence Fourcade, Florence Geneste, Isabelle Soutrel, Didier Floner, et al.. Direct electrochemical oxidation of a pesticide, 2,4-dichlorophenoxyacetic acid, at the surface of a graphite felt electrode: Biodegradability improvement. Comptes Rendus. Chimie, 2015, 18 (1), pp.32-38. 10.1016/j.crci.2014.05.004 . hal-01026437

\section{HAL Id: hal-01026437 \\ https://hal.science/hal-01026437}

Submitted on 3 Oct 2014

HAL is a multi-disciplinary open access archive for the deposit and dissemination of scientific research documents, whether they are published or not. The documents may come from teaching and research institutions in France or abroad, or from public or private research centers.
L'archive ouverte pluridisciplinaire HAL, est destinée au dépôt et à la diffusion de documents scientifiques de niveau recherche, publiés ou non, émanant des établissements d'enseignement et de recherche français ou étrangers, des laboratoires publics ou privés. 
Direct electrochemical oxidation of a pesticide, 2,4-Dichlorophenoxyacetic acid, at the surface of a graphite-felt electrode - Biodegradability improvement

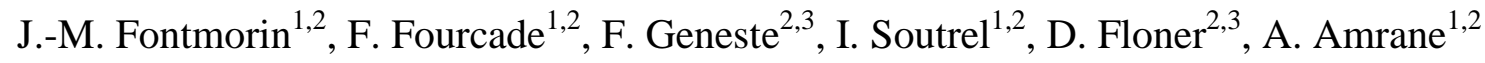

${ }^{1}$ Ecole Nationale Supérieure de Chimie de Rennes / Université de Rennes 1, CNRS, UMR 6226, 11 allée de Beaulieu, CS 50837, 35708 Rennes cedex 7, France.

${ }^{2}$ Université de Rennes 1, CNRS, UMR 6226, Equipe Matière Condensée et Systèmes Electroactifs, Campus de Beaulieu, 35042 Rennes cedex, France.

${ }^{3}$ Université Européenne de Bretagne, 5 boulevard Laënnec, 35000 Rennes, France.

*Corresponding author: Phone: (+33) 2232381 55; Fax: (+33) 22323 81 20;

abdeltif.amrane@univ-rennes1.fr 


\begin{abstract}
Pesticides biorecalcitrance can be related to the presence of complex aromatic chain or the presence of specific bonds, such as halogenated bonds, which are the most widespread. In order to treat this pollution at source, namely in the case of highly concentrated solutions, selective processes, such as electrochemical processes, can appear especially relevant to avoid possible generation of toxic degradation products and to improve biodegradability in view of a subsequent biological mineralization. 2,4-D was found to be electroactive in oxidation but not in reduction and the absence of hydroxyl radicals formation during the electrochemical step was demonstrated showing that the pretreatment can be considered as a 'direct' electrochemical process instead of an advanced electrochemical oxidation process. The presence of several degradation products in the oxidized effluent showed that the pretreatment was not as selective as expected. However, the relevance of the proposed combined process was confirmed since the overall mineralization yield was close to $93 \%$.
\end{abstract}

Keywords: 2,4-D; Combined process; Electrochemical process; Biological treatment; Carbon felt electrode.

\title{
1. Introduction
}

The large accumulation of endocrine disruptors, in continental and marine natural waters are the consequence of the worldwide general application of intensive agricultural methods, the large-scale development of the agrochemical and food industry and the high levels found in some specific effluents (textile, pharmaceutical, hospital waste...). For instance, in the Brittany region (France), the Regional Direction of the Environment (DIREN) observes a contamination of the Brittany Rivers by phytosanitary products, including pesticides, which can interfere with hormone systems of living beings (endocrine disruptors) [1]. Partly 
responsible for this pollution, low volumes containing high concentrations of persistent organic pollutants, in the range of concentrations found in some specific industrial and agricultural effluents (unused treatment solution, spray, machine and container washing....) [2], can result in large polluted volumes which are difficult to treat owing to their low concentrations. One solution would be therefore to treat pollution at source, as intended in this study.

Pesticides impact on the environment is complex and varied according to various factors, such as toxicity and ecotoxicity of the parent molecule or by-product metabolites, synergistic effects with other pollutants, length of the half-life, exposure time and dose, etc. Various acute or chronic poisoning effects on human health have been described [3-6]. There is therefore an urgent need for efficient processes for their removal and owing to the possible toxicity of the by-product metabolites, total mineralization is mainly targeted.

For this purpose, biological processes, the most cost-effective for wastewater treatment, which are destructive and have been extensively studied [7-11] do not always appear relevant for the removal of recalcitrant compounds, owing to their low biodegradability.

Contrarily, physico-chemical techniques have proved their efficiency for their removal. Among them, Advanced Oxidation Processes constitute the most important and widely documented group $[2,12,13]$, owing to the high reactivity of the free ${ }^{\bullet} \mathrm{OH}$ radicals produced. However and due to the lack of selectivity of the free radicals, possible toxic by-products can be generated, which in some cases can appear more toxic than the parent compounds $[14,15]$. Consequently, the mineralization time is of major importance; too low process time can result in toxic by-products, while long process time to ensure total mineralization can induce high energy costs.

It is noteworthy that pesticides biorecalcitrance can be related to the presence of complex aromatic chain or to the presence of specific bonds, such as nitro- or halogenated bonds. For 
instance, among the most used pesticides, a three-quarter of them contains halogenated bonds; and the presence of chlorine atoms on phenyl ring is a factor that favors the toxicity of aryl compounds [16]. From this, the development of processes targeting a selective attack of specific functional groups to improve the biodegradability of a given effluent can constitute another approach to treat effluents containing pesticides.

Indeed, if agricultural effluents are for instance considered, pesticides levels can reach $500 \mathrm{mg}$ $\mathrm{L}^{-1}[2]$, as it is the case in farm bottom tanks. Hence, a selective attack of specific functional groups, can constitute a relevant solution to relieve AOPs drawbacks. The generation of possible toxic by-products could thus be avoided owing to the expected control of the resulting by-products as well as the high energy costs since total mineralization is not the objective owing to the expected improvement of biodegradability.

For this purpose and in the case of an electroactive target compound, its electrochemical oxidation or reduction can be carried out for its degradation. Total mineralization can be subsequently completed during biological treatment, since the potential advantages of the strategy of combining physico-chemical and biological processes to treat contaminants in wastewater were previously underlined [17-20]. However, the literature dealing with the use of direct electrochemical oxidation/reduction for effluent pre-treatment remains scarce. Doan et al. [21] and Ghafari et al. [22] coupled an electrochemical process and a biological treatment for the removal of heavy metals and nitrate, respectively; while regarding organic pollutants, up to now our work seem to be the only available dealing with the combination of a direct electrochemical process and a biological treatment. It was investigated for the removal of phosmet, an organophosphorous insecticide [23], some antibiotics, tetracycline [24] and sulfamethazine [25], and a chlorinated phenoxy herbicide 2,4-dichlorophenoxyacetic acid $[26,27]$. 
The promising results obtained regarding 2,4-D should be underlined [28,29], since halogenated pesticides are the most widespread pesticides. Indeed, it was shown that mild oxidation of the target compound can be sufficient to improve biodegradability [28] allowing subsequent biological treatment [29]. However in view of the targeted selectivity, the nature of the electrochemical process should be clearly elucidated, namely the involvement or not of free hydroxyl radials in pesticide's oxidation; it is discussed in this study.

However, the production of this highly reactive species is closely linked to the electrode material used and to some operating parameters such as oxygen overvoltage. If some electrodes (boron-doped diamond electrodes for instance) are well-known as powerful candidates for ${ }^{\bullet} \mathrm{OH}$ generation, it is not at all obvious for some other materials, such as graphite felt, the material used in the laboratory [23,25-27]. Indeed, the use of a graphite felt working electrode with a high specific area in a flow electrochemical cell [30] allows the electrochemical reaction of the electroactive species at macroscale level with low electrolysis times. Even if mechanisms involving ${ }^{\bullet} \mathrm{OH}$ have been previously suggested for studies based on the use of graphite felt [31], to our knowledge such production at the surface of such electrode material has never been demonstrated up to now. However, this question appears to be of major importance to understand the electrochemical oxidation phenomena occurring during the use of such material and to confirm the specificity and selectivity of the considered processes, namely a direct reaction at the electrode surface. For this purpose, three points have to be considered, the nature of the working electrode, the experimental conditions and the indirect determination of the hydroxyl radicals; these points are investigated in this study. In addition and to complete mechanism knowledge, the electrochemical reaction of 2,4-D at the electrode was also examined.

Biological treatment involving activated sludge was then considered to examine the efficiency of the electrochemical pretreatment. 


\section{Materials and Methods}

\subsection{Chemicals}

2,4-dichlorophenoxyacetic acid (2,4-D) (98\%) was purchased from Alfa Aesar (Schiltigheim, France). Chlorohydroquinone (85\%) was purchased from Sigma-Aldrich (Saint-Quentin Fallavier, France). Acetonitrile (ACN) and formic acid were LC/MS grade from JT Baker (Deventer, Netherlands). All standards were prepared with ultra pure water (PurelabOptionsQ7/15, Elga, 18.2 M $\Omega \mathrm{cm})$.

\subsection{Electrochemical pre-treatment}

The electrochemical pre-treatment was based on a home-made flow cell [28]. Graphite felt used as working electrode was supplied by Mersen (RVG 4000 - Mersen, Paris La Défense, France) [27]. The dimensions of the graphite felt were $48 \mathrm{~mm}$ diameter and $12 \mathrm{~mm}$ width.

Two interconnected stainless steel plates were used as counter-electrodes and compartments were separated by cationic exchange membranes (Ionac 3470 - Lanxess SAS, Courbevoie, France). The reference electrode (Saturated Calomel Electrode - SCE) was positioned in the middle of the graphite felt. To ensure a good homogeneity of the potential distribution in the three dimensional working electrode, the felt was located between the two counter-electrodes [30]. The electrolyte solution percolated the porous electrode and the flow rate was monitored by a Gilson minipuls 2 peristaltic pump (Middleton, WI, USA). A VersaSTAT 3 potentiostat (Ametek/Princeton Applied, Elancourt, France) was used to control the potential.

\subsection{Biological process}

After only one pass through the electrochemical flow-cell, the effluent was collected for the subsequent biological treatment, which was carried out in aerobic conditions, using activated 
sludge purchased from the local wastewater treatment plant (Station de Beaurade, Rennes, France). Before use and to avoid any residual carbon or mineral nutrient, it was treated as previously detailed [26].

Experiments were carried out in $250 \mathrm{~mL}$ erlenmeyer flasks containing $100 \mathrm{~mL}$ of medium, stirred at $250 \mathrm{rpm}$, kept at $30^{\circ} \mathrm{C}$ and triplicated to ensure the reproducibility of the results. The electrolyzed solution (initially $500 \mathrm{mg} \mathrm{L}^{-1}$ 2,4-D) was diluted (five times dilution) to allow a direct comparison to non-treated 2,4-D (100 $\left.\mathrm{mg} \mathrm{L}^{-1}-[26]\right)$. Minerals were spiked in the medium as highly concentrated solutions to reach the following initial composition (mg $\left.\mathrm{L}^{-1}\right): \mathrm{Na}_{2} \mathrm{HPO}_{4}, 334 ; \mathrm{K}_{2} \mathrm{HPO}_{4}, 208 ; \mathrm{KH}_{2} \mathrm{PO}_{4}, 85 ; \mathrm{CaCl}_{2}, 27.4 ; \mathrm{MgSO}_{4} .7 \mathrm{H}_{2} \mathrm{O}, 22.6 ; \mathrm{NH}_{4} \mathrm{Cl}, 75$; $\mathrm{FeCl}_{3} \cdot 6 \mathrm{H}_{2} \mathrm{O}, 0.26$; and the initial $\mathrm{pH}$ was adjusted to $7.0 \pm 0.2$. Activated sludge was added in order to have initial concentration of $0.5 \mathrm{~g} \mathrm{~L}^{-1}$ of dry matter. Samples $(5 \mathrm{~mL})$ were taken regularly and filtered through $0.45 \mu \mathrm{m}$-syringe filters for measurements.

\subsection{Analysis}

Measurements of the residual 2,4-D and chlorohydroquinone concentration were performed by HPLC (High Pressure Liquid Chromatography) (Milford, USA) system involving a pump Waters 600, fitted with a Phenomenex Kinetex ${ }^{\circledR}$ C18 $2.6 \mu \mathrm{m}$ column $(4.6 \mathrm{~mm} \times 100 \mathrm{~mm})$, along with a Waters 996 Photodiode array detector, a Waters 717 ph Autosampler and controlled through an Empower ${ }^{\circledR} 2$ program. The mobile phase consisted of acetonitrile and trifluoroacetic acid (TFA) $0.1 \%$ in ultra-pure water with a ratio of $30 / 70$ at $1 \mathrm{~mL} \mathrm{~min}^{-1}$.

\subsubsection{Dissolved Organic Carbon (DOC) measurements}

Solutions were filtered on Satorius Stedim Minisart $0.45 \mu \mathrm{m}$ GF prefilters (Goettingen, Germany). DOC was measured by means of a TOC- $\mathrm{V}_{\mathrm{CPH} / \mathrm{CPN}}$ Total Organic Analyzer 
Schimadzu. Reproducible DOC values were always obtained using the standard NPOC (Non Purgeable Organic Carbon) method.

\subsubsection{Chemical Oxygen Demand (COD) and Biological Oxygen Demand ( $\left.B O D_{5}\right)$}

Chemical Oxygen Demand (COD) was measured by means of a Test Nanocolor ${ }^{\circledR}$ CSB 160 from Macherey-Nagel (Düren, Germany).

$\mathrm{BOD}_{5}$ measurements were carried out in Oxitop IS6 (WTW, Alès, France). Activated sludge provided by a local wastewater treatment plant (Rennes Beaurade, Bretagne, France) was used to inoculate duplicate flasks and the initial microbial concentration was set to $0.5 \mathrm{~g} \mathrm{~L}^{-1}$. More details regarding the experimental procedure can be found in previous papers [26,27].

\section{Results and Discussion}

\subsection{Electrochemical behavior of 2,4-D}

Electrochemical behavior of 2,4-D in acidic medium $(\mathrm{pH} \approx \mathrm{pKa}=2.8$, naturally obtained when 2,4-D was dissolved in water) showed an electroactivity in reduction and in oxidation [27]. 2,4-D electrolysis in reduction showed a disappearance of the first reduction signal, which was however not confirmed by HPLC analysis, which indicated no 2,4-D degradation. The disappearance of the reductive signal was found to be closely related to its anionic or molecular form, and thus to the $\mathrm{pH}$ of the medium, since the reductive signal disappeared at alkaline final electrolysis $\mathrm{pH}$ (11), while it was recovered after medium acidification to the initial pH value (2.8) (Fig.1).

This electrochemical behavior closely related to the $\mathrm{pH}$ and coupled to the analytical results obtained by liquid chromatography led to exclude the initial assumption of a $\mathrm{C}-\mathrm{Cl}$ bond cleavage and to consider instead a reduction of the carboxylic acid function of 2,4-D. Indeed, the carboxylic acid can undergo a one-electron reaction to yield the corresponding 
carboxylate anion, which is accompanied by hydrogen release (Reaction 1 - Fig.2); and the reduction of the formed carboxylate appears difficult in the considered solvent, water. The carboxylic acid can also undergo 2-, 4- or 6- electron reductions to give the corresponding aldehyde, alcohol or alcane, respectively (Reactions 2 to 4 - Fig.2); these reactions can however occur in acidic conditions avoiding the carboxylate reduction [32].

The lack of reduction wave was expected at alkaline $\mathrm{pH}$, since its anionic form largely predominated owing to the 2,4-D pKa (2.8); this characteristic wave can only be observed in the presence of the protonated form of the compound, namely for $\mathrm{pH}$ values below 4 . The transformation of the carboxylic acid into its ester form should allow to avoid its carboxylate reduction, which would be helpful to validate the above assumption. Thus, the diethyl ester of 2.4-D was prepared by the reaction of 2.4-D with oxalyl chloride to form the acyl chloride derivative and then with ethanol. However, it was not possible to analyze the synthesized ester in water owing to its low solubility, leading to perform cyclic voltammetry analyses in acetonitrile. As shown in Fig.3, the synthesized ester was reduced at a lower potential (-1.75 V/ECS) than the initial compound (-1.5 V/ECS). Consequently, the wave observed during 2,4-D reduction was linked to the reduction of the acid to acetate instead of the aromatic ring dechlorination.

The electrochemical behavior of 2,4-D was then examined in oxidation, and hence a similar approach was considered, namely cyclic voltammetry analysis prior to electrolysis to confirm pretreatment feasibility. An oxidation wave was observed at 1.6 V/ECS (Fig.4).

To confirm 2,4-D electroactivity in oxidation, the absence of $\mathrm{pH}$ impact on its electrochemical behavior was checked and confirmed, since the oxidation wave was observed at both acidic and alkaline $\mathrm{pH}$ (Fig.4). 


\subsection{Nature of the electrochemical process}

Since no 2,4-D degradation was detected during cathodic reduction experiments in aqueous medium, electrolyses were therefore performed in oxidation. However, one major question remained, which was the nature of the electrochemical process involved in 2,4-D oxidation: are free radicals involved in 2,4-D degradation?

Electrodes can be classified as 'actives' and 'non-actives' according to their reactivity vis-avis the reaction of oxygen formation [33]. In a first step, plane graphite electrode was used to allow a fine observation of oxygen formation on the material (graphite). The obtained results were then compared to well-known electrode materials, such as platinum or vitreous carbon. At $\mathrm{pH} 2.7$, namely close to the experimental conditions in the presence of $2,4-\mathrm{D}$, it can be observed an oxygen release from about 1.5-1.6 V/SCE on graphite and platinum and from 1.6 et $1.7 \mathrm{~V} / \mathrm{SCE}$ for vitreous carbon (it should be remembered that on a BDD it is usually observed near 2.5 V/SCE) [34]. The shape of the curve recorded on graphite suggested a resistive character of the material before oxygen release, which may be related to the nature of the electrode. This phenomenon was systematically observed, irrespective of meticulous electrode polishing, long degassing time or an electrochemical surface cleaning, namely a chronoamperometry at $0 \mathrm{~V} / \mathrm{SCE}$ before cyclic voltammetry analyses. This relatively early oxygen release on graphite suggested an 'active' electrode nature, which was not in favor of • $\mathrm{OH}$ production in the considered experimental conditions.

\subsubsection{The nature of the working electrode}

Current densities can vary according to the considered surface as highlighted in Fig.5. A cylindrical graphite felt of $10 \mathrm{~mm}$ diameter and $12 \mathrm{~mm}$ height was considered. The total geometric surface of the cylinder was $5.34 \mathrm{~cm}^{2}$. From BET analysis and the felt density (given 
by the manufacturer), $0.7 \mathrm{~m}^{2} \mathrm{~g}^{-1}$ and $0.088 \mathrm{~g} \mathrm{~cm}^{-3}$, respectively, the BET surface was $580 \mathrm{~cm}^{2}$ (the cylinder volume was $0.942 \mathrm{~cm}^{3}$ ), namely a ratio close to 109 between both surfaces. However, it can be observed that the surface given by the BET is most likely overestimated, since deduced from the adsorbed nitrogen amount; while and owing to its low size, nitrogen can penetrate pores which are not accessible to water. Another and probably more realistic approach is to use cyclic voltammetry and especially the oxidation (or reduction) current of potassium ferricyanide $\left(\mathrm{K}_{3}\left[\mathrm{Fe}(\mathrm{CN})_{6}\right], 4.9 \mathrm{mM}\right)$ to estimate the electrochemical electrode surface. Indeed, the ferricyanide peak current is linked to the electrode surface through the following relation [35]:

$$
i_{p}=\left(2,69 \times 10^{5}\right) n^{1 / 2} A D_{0}^{1 / 2} C_{0}^{8} v^{1 / 2}
$$

With $i_{p}$ the peak current intensity, $n$ the number of exchanged electrons (1), $A$ the electrode surface $\left(\mathrm{cm}^{2}\right), D_{0}$ the ferricyanide diffusion coefficient $\left(0.7610^{-5} \mathrm{~cm}^{2} \mathrm{~s}^{-1}\right.$ in $\left.\mathrm{KCl} 0.1 \mathrm{M}\right), C_{0}$ the ferricyanide concentration $\left(\mathrm{mol} \mathrm{cm}^{-3}\right)$ and $v_{0}$ the sweep rate $\left(0.1 \mathrm{~V} \mathrm{~s}^{-1}\right)$.

$0.5 \mathrm{M}$ phosphate buffer at $\mathrm{pH} 2.7$ was used and an approximate diffusion coefficient value of $0.76 \times 10^{-5} \mathrm{~cm}^{2} / \mathrm{s}$ was considered for ferricyanide (in $\mathrm{KCl} 0.1 \mathrm{M}$ at $\left.25^{\circ} \mathrm{C}\right)(273,274)$. From this, the electrochemical surface was $55.05 \mathrm{~cm}^{2}$, namely between the geometric surface and that deduced from the BET measure.

If compared to plane graphite electrode, the more linear oxygen release observed on the working electrode highlighted a lower conductivity (Fig.6). The geometric surface seems to minimize the active surface area of the electrode owing to the high current density obtained (Fig.6). In addition to the external volume, the internal felt volume seems therefore involved in the electrochemical reaction. Contrarily, the BET surface seems to overestimate the active surface area owing to the negligible current density obtained. The electrochemical surface 
appears consistent if the beginning of oxygen release, occurring at 1.5-1.6 V/SCE, namely close to that observed on a plane graphite felt, is considered.

From this, the oxidation potential of water on graphite felt remains low (1.5-1.6 V/SCE), showing that it can be considered as an 'active' electrode and hence the nature of the working electrode was also in favour of a direct 2,4-D oxidation rather than ${ }^{\bullet} \mathrm{OH}$ generation.

\subsubsection{The operating conditions}

The electrochemical oxidation of 2,4-D was performed at $1.6 \mathrm{~V} / \mathrm{SCE}$. Only few studies involving chronoamperometry are available in the literature. However, analytical studies show that the potentials corresponding to the currents applied to BDD electrodes in view of herbicides degradation can easily exceed 3.2 V/SCE [36], namely highly above the oxidation potential of water on a graphite electrode.

The applied current densities varied widely according to the electrode materials used, the operating conditions (electrolyte and pollutant concentrations, temperature....), but usually remain in the range some tens to a hundred $\mathrm{mA} \mathrm{cm}^{-2}$ [37-39]. The difficulty to determine the current density applied on the graphite felt has been previously discussed. Indeed, for the graphite felt implemented in the percolation flow-cell $(48 \mathrm{~mm} \times 12 \mathrm{~mm})$, the geometric surface was $54.3 \mathrm{~cm}^{2}$ and those given by the BET and electrochemically were 13300 and $1270 \mathrm{~cm}^{2}$. From this and for a usual current of $200 \mathrm{~mA}$, the current density values were 3.7 , 0.015 and $0.157 \mathrm{~mA} \mathrm{~cm}^{-2}$ for the geometric, the BET and the electrochemical surfaces, respectively. Since the active surface should be considered with caution, the current densities appeared low if compared to those generally reported in the literature regarding AOPs, namely involving hydroxyl radicals formation (in the magnitude of some tens $\mathrm{mA} \mathrm{cm}^{-2}$ ). 


\subsubsection{Hydroxyl radicals' dosage}

The above arguments are based on analytical observations and assumptions; while the best proof of radicals formation remains their dosage. ${ }^{\bullet} \mathrm{OH}$ are known for their strong reactivity with benzene (kinetic rate constant $\mathrm{k}=8.10^{9} \mathrm{~L} \mathrm{~mol}^{-1} \mathrm{~s}^{-1}$ ), showing the relevance of this compound as a radical scavenger [40,41]. Since phenol is the sole product of benzene hydroxylation, the amount of ${ }^{\bullet} \mathrm{OH}$ produced can be deduced from the HPLC monitoring of benzene degradation $(\lambda=200 \mathrm{~nm})$ linked to phenol production $(\lambda=270 \mathrm{~nm})$. The absence of benzene oxidation at the electrode at 1.6 V/SCE was first confirmed. Electrolysis was then performed in the flow-cell with recycling of the electrolyzed solution. Neither noticeable benzene degradation nor phenol formation was observed, confirming the absence of ${ }^{\bullet} \mathrm{OH}$ formation in the considered experimental conditions, despite the recycling of the electrolysis solution through the cell to favor phenol accumulation.

In the light of the above results, possible involvement of ${ }^{\circ} \mathrm{OH}$ can be rejected in the mechanism of 2,4-D oxidation. Consequently, the proposed pretreatment can be considered as a 'direct' electrochemical process instead of an advanced electrochemical oxidation process.

\subsection{Feasibility of the combined process}

The $\mathrm{BOD}_{5} / \mathrm{COD}$ ratio increased from 0.04 initially to 0.25 for the oxidized solution. Owing to this biodegradability improvement, and even if the limit of biodegradability $(0.4[19,42])$ was not reached, a biological treatment of the pretreated solution was performed.

Prior to the biological treatment step, possible biosorption on activated sludge of 2,4-D on the one hand and the major by-product, chlorohydroquinone [27], for the electrolyzed effluent on the other hand was assessed and was found to be negligible [26]. 
Evolution of the mineralization, as well as 2,4-D and Chlorohydroquinone, during activated sludge culture are displayed in Figure 7; the low 2,4-D amount (Fig.7) should be related to its almost total removal at the end of the electrochemical pretreatment (96\% removal), while mineralization level remained limited, 34\% [26]. Contrarily to the behavior found for nonpretreated 2,4-D solutions, for which an acclimation period of seven days was needed before noticeable 2,4-D degradation can be observed [26], no significant lag phase can be noticed in the case of the electrolyzed effluent. Indeed, a $66 \%$ decrease of the initial DOC amount in the pretreated effluent was measured after only two days of culture (Fig.7), without significant involvement of biosorption; illustrating a readily assimilation of some degradation products. Mineralization continued until day 5 of culture, since $77 \%$ mineralization yield was measured. Beyond this time, no really significant decrease of the initial dissolved organic carbon was measured since only less than $10 \%$ further mineralization was obtained after 21 days of culture, leading to a final mineralization yield during the biological treatment of $85 \%$, namely 93\% overall mineralization yield by means of the combined process. It should be observed that a biological treatment carried out in similar conditions but lacking of any carbon source, especially 2,4-D, was used as a "blank" test; its DOC value, namely $17 \mathrm{mg} \mathrm{L}^{-1}$, was considered as the reference (100\% mineralization) [26]. Residual 2,4-D and the main degradation product, chlorohydroquinone, were also monitored showing their total removal within the first two days of biological treatment for the former and after 14 days for the latter, in agreement with the total 2,4-D removal also observed after 14 days culture for the nonpretreated effluent [26]. Owing to the presence of non-negligible residual DOC amount, the presence of refractory degradation products in the oxidized effluent can be assumed, which was not assimilated even after 21 days of activated sludge culture. Activated sludge acclimation to the by-products should be therefore subsequently considered to improve the biological mineralization of the electrolyzed solution. 


\section{Conclusion}

The feasibility of an electrochemical process for pesticide pretreatment was shown, since it improved significantly the mineralization rate and thus significantly shortened the length of the biological treatment if compared to non-pretreated 2,4-D solutions. The absence of hydroxyl radical formation was demonstrated showing that the pretreatment can be considered as a 'direct' electrochemical process instead of an advanced electrochemical oxidation process. However, its selectivity was not as high as expected owing to the various degradation products identified [27] and to the biorefractory degradation products remaining at the end of activated sludge culture. Improving selectivity constitutes the main objective to continue this work. For this purpose and since most of the persistent organic pollutants being halogenated compounds, the specific removal of halogen groups from the substrate could be considered. Works are in progress in the laboratory regarding the electrocatalytic reduction of carbonhalogen bonds of some halogenated target compounds, as well as the influence of the dehalogenation on the biodegradability of these compounds.

\section{Acknowledgments}

We thank Dr Elisabet Dunach-Clinet for helpful discussions. 


\section{References}

[1] C. Ferragu, I. Tron, Pesticides et Santé: Etat des connaissances sur les effets chroniques en 2009, Observatoire Régional de Santé Bretagne, 2010.

[2] S. Chiron, A.R. Fernandez-Alba, A. Rodriguez, E. Garcia-Calvo, Water Res. 34 (2000) 366.

[3] T.E. Arbuckle, Z. Lin, L.S. Mery, Environ. Health Perspectives 109 (2001).

[4] T.E. Arbuckle, L.E. Sever, Crit. Rev. Toxicol. 28 (1998) 229.

[5] L. Roldán-Tapia, T. Parrón, F. Sánchez-Santed, Neurotoxicol. Teratol. 27 (2005) 259.

[6] L. Lauria, L. Settimi, A. Spinelli, I. Figà-Talamanca, Reproductive Toxicol. 22 (2006) 425.

[7] B.V. Chang, C.M. Yang, C.H. Cheng, S.Y. Yuan, Chemosphere 55 (2004) 533.

[8] N. Dafale, N.N. Rao, S.U. Meshram, S.R. Wate, Bioresour. Technol. 99 (2008) 2552.

[9] K.M. Crowe, A.A. Bushway, R.J. Bushway, K. Davis-Dentici, J. Food Sci. 72 (2007) 293.

[10] T. Eizuka, A. Ito, T. Chida, J. Pestic. Sci. 28 (2003).

[11] H.N. Gavala, F. Alatriste-Mondragon, R. Iranpour, B.K. Ahring, Chemosphere 52 (2003) 673.

[12] T. Oppenländer, Photochemical Purification of Water and Air. Advanced Oxidation Processes (AOPs): Principles, Reaction Mechanisms, Reactor Concepts. Wiley-VCH., 2003.

[13] M.I. Badawy, M.Y. Ghaly, T.A. Gad-Allah, Desalination 194 (2006) 166.

[14] N.P. Tantak, S. Chaudhari, J. Hazard. Mater. 3 (2006) 698.

[15] D. Chebli, F. Fourcade, S. Brosillon, S. Nacef, A. Amrane, J. Chem. Technol. Biotechnol. 85 (2010) 555.

[16] R.W. Okey, H.D. Stensel, Water Res. 30 (1996) 2206.

[17] J.P. Scott, D.F. Ollis, Environ. Prog. 14 (1995) 88. 
[18] J.P. Scott, D.F. Ollis, J. Adv. Oxid. Technol. 2 (1997) 374.

[19] C. Pulgarin, M. Invernizzi, S. Parra, V. Sarria, R. Polania, P. Péringer, Catal. Today 54 (1999) 341.

[20] M.J. Farré, S. Brosillon, X. Domènech, J. Peral, J. Photochem. Photobiol. A-Chem. 189 (2007) 364.

[21] H.D. Doan, J. Wu, R. Mitzakov, J. Chem. Technol. Biotechnol. 81 (2006) 1398.

[22] S. Ghafari, M. Hasan, M.K. Aroua, Bioresour. Technol. 99 (2008) 3965.

[23] N. Alonso-Salles, F. Fourcade, F. Geneste, D. Floner, A. Amrane, J. Hazard. Mater. 181 (2010) 617.

[24] D. Belkheiri, F. Fourcade, F. Geneste, D. Floner, H. Aït-Amar, A. Amrane, Sep. Purif. Technol. 83 (2011) 151.

[25] I. Saidi, I. Soutrel, F. Fourcade, A. Amrane, D. Floner, N. Bellakhal, F. Geneste, J. Electroanal. Chem. 707 (2013) 122.

[26] J.M. Fontmorin, S. Huguet, F. Fourcade, F. Geneste, D. Floner, A. Amrane, Biochem. Eng. J. 70 (2013) 17.

[27] J.M. Fontmorin, S. Huguet, F. Fourcade, D. Floner, F. Geneste, A. Amrane, Chem. Eng. J. 195-196 (2012) 208.

[28] J.M. Fontmorin, S. Huguet, F. Fourcade, F. Geneste, D. Floner, A. Amrane, Chem. Eng. J. 195-196 (2012).

[29] J.M. Fontmorin, F. Fourcade, F. Geneste, D. Floner, S. Huguet, A. Amrane, Biochem. Eng. J. 70 (2013).

[30] C. Moinet, Le Journal de Physique IV 4 (1994) 175.

[31] A.M. Polcaro, S. Palmas, Ind. Eng. Chem. Res. 36 (1997) 1791.

[32] O. Hammerich, H. Lund, Organic electrochemistry, CRC Press, New York, 2000. 
[33] A.J. Bard, M. Stratmann, Encyclopedia of Electrochemistry, Wiley-VCH Verlag GmbH \& Co, KGaA, Weinheim, 2007.

[34] R.L. McCreery, Chem. Rev. 108 (2008) 2646.

[35] A.J. Bard, L.R. Faulkner, Electrochemical methods: Fundamentals and applications, Wiley, New York, 2001.

[36] B. Boye, E. Brillas, B. Marselli, P.-A. Michaud, C. Comninellis, G. Farnia, Electrochem. Acta 51 (2006) 2872.

[37] C. Flox, P.L. Cabot, F. Centellas, J.A. Garrido, R.M. Rodriguez, C. Arias, Chemosphere 64 (2006) 892.

[38] E. Brillas, B. Boye, I. Sirés, J.A. Garrido, R.M. Rodriguez, C. Arias, Electrochem. Acta 49 (2004) 4487.

[39] M. Panizza, Importance of electrode material in the electrochemical treatment of wastewater containing organic pollutants, in: C. Comninellis, G. Chen (Eds.), Electrochemistry for the environment, Springer, New York, 2010, pp. 25-54.

[40] J. Kochany, J.R. Bolton, Environ. Sci. Technol. 26 (1992) 262.

[41] X.-M. Pan, M.N. Schuchmann, C. von Sonntag, J. Chem. Soc., Perkin Trans. 2 (1993) 289.

[42] V. Sarria, S. Parra, N. Adler, P. Péringer, N. Benitez, C. Pulgarin, Catal. Today 76 (2002) 301. 
Figure legends

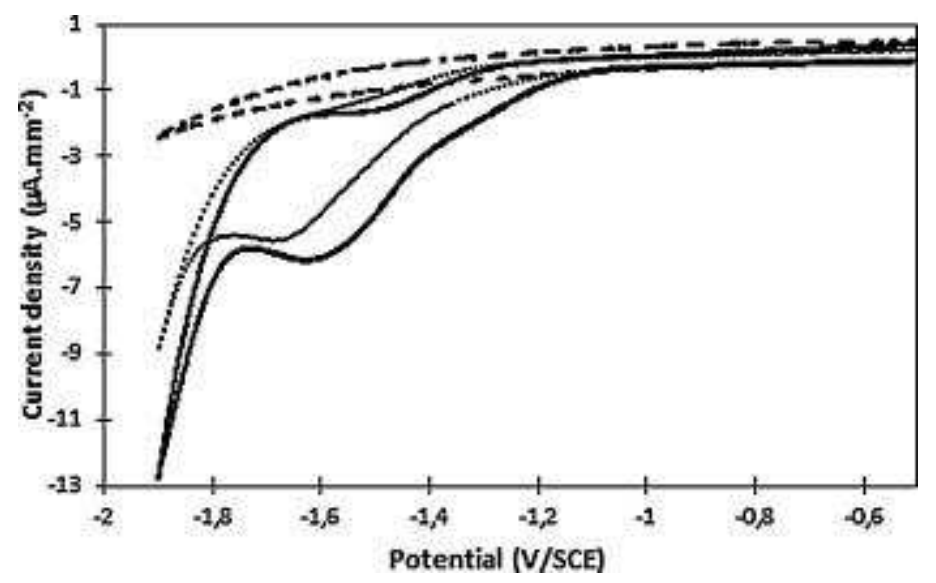

Figure 1. Cyclic voltammetry of a 2,4-D solution $\left(500 \mathrm{mg} \mathrm{L}^{-1}\right)$ at $\mathrm{pH} 2.8$ (dots), at $\mathrm{pH} 11$ (dashes) and at pH 2.8 after re-acidification (full line).Voltammograms recorded at $100 \mathrm{mV} \mathrm{s}^{-}$ ${ }^{1}$ in $\mathrm{Na}_{2} \mathrm{SO}_{4} 0.1 \mathrm{~mol} \mathrm{~L}^{-1}$ on a glassy carbon electrode $\left(7 \mathrm{~mm}^{2}\right)$.

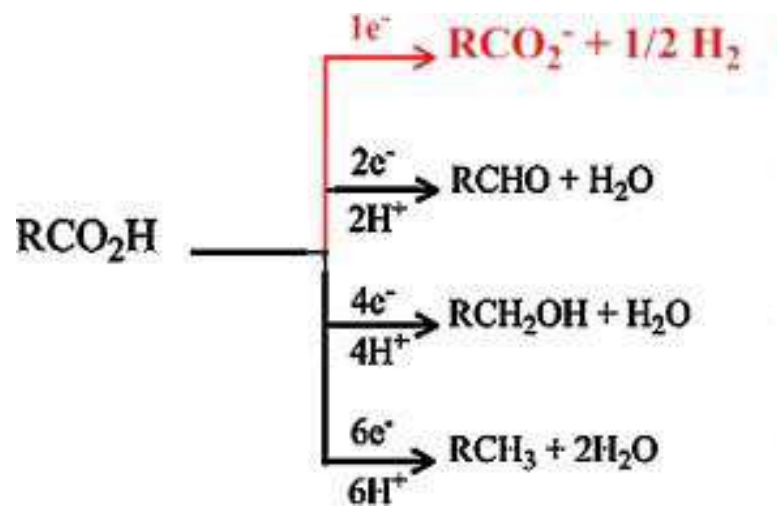

Figure 2. Possible reactions for the reduction of the carboxylic function of 2,4-D. 


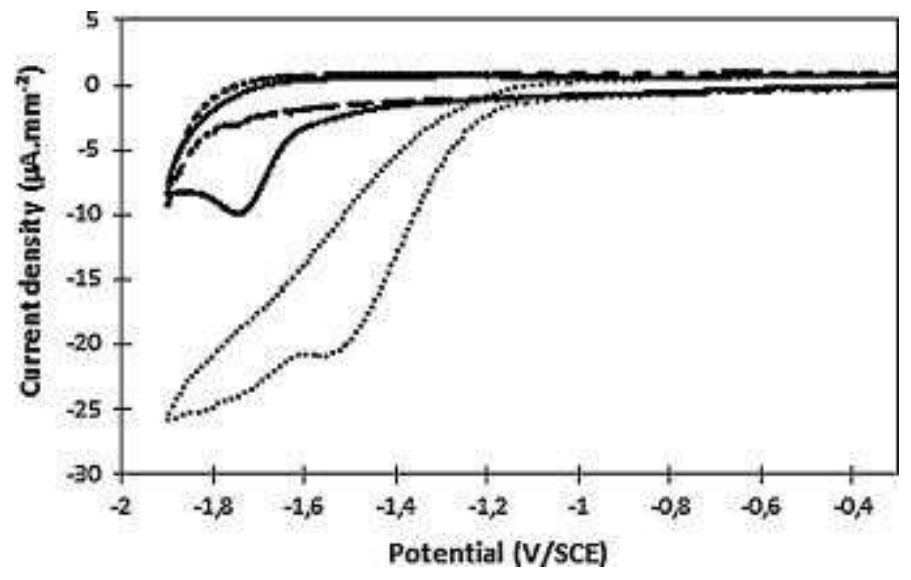

Figure 3. Cyclic voltammetry of 2,4-D $\left(20 \mathrm{mmol} \mathrm{L}^{-1}-\right.$ dots $)$ and its ester form $\left(20 \mathrm{mmol} \mathrm{L}^{-1}\right.$ - full line $)$ in acetonitrile $\left(\mathrm{KPF}_{6} 0.1 \mathrm{~mol} \mathrm{~L}{ }^{-1}\right.$ - blank: dashes $)$ on a glassy carbon electrode $(7$ $\left.\mathrm{mm}^{2}\right)$. Voltammograms recorded at $100 \mathrm{mV} \mathrm{s}^{-1}$.

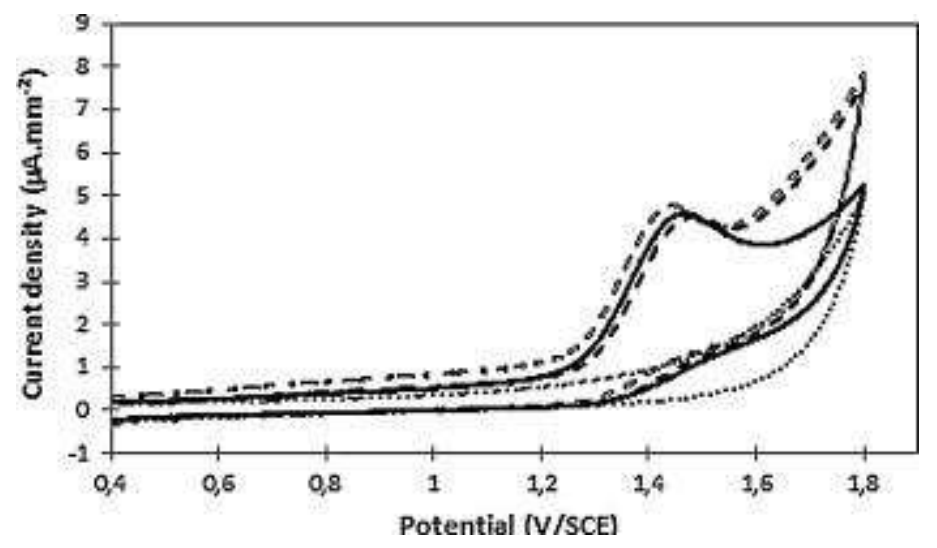

Figure 4. Cyclic voltammetry of $\mathrm{Na}_{2} \mathrm{SO}_{4} 0.1 \mathrm{~mol} \mathrm{~L}^{-1}$ as supporting electrolyte (dots), in the presence of $100 \mathrm{mg} \mathrm{L}^{-1}$ 2,4-D at $\mathrm{pH} 3.6$ (full line), at pH 11 (empty dashes) and at $\mathrm{pH} 2.8$ after re-acidification (full dahes).Voltammograms recorded at $100 \mathrm{mV} \mathrm{s}^{-1}$ on a glassy carbon electrode $\left(7 \mathrm{~mm}^{2}\right)$. 


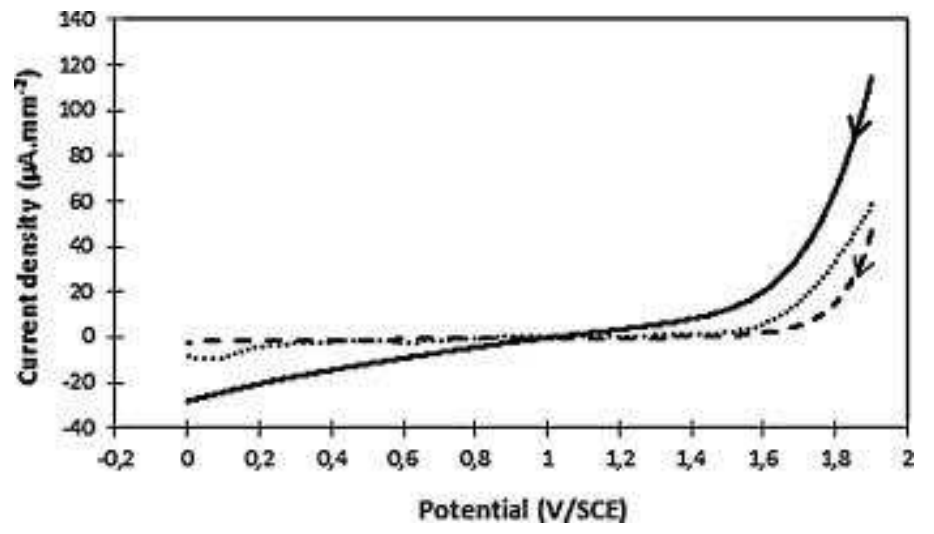

Figure 5. Oxygen evolution observed in phosphate buffer $(\mathrm{pH} 2.7)$ on various electrode materials: graphite (full line, $12.6 \mathrm{~mm}^{2}$ ), vitreous carbon (dashes, $7 \mathrm{~mm}^{2}$ ) and platinum (dots, $4.5 \mathrm{~mm}^{2}$ ). The scan direction was indicated by the arrow. Voltammograms recorded at 100 $\mathrm{mV} \mathrm{s}^{-1}$.

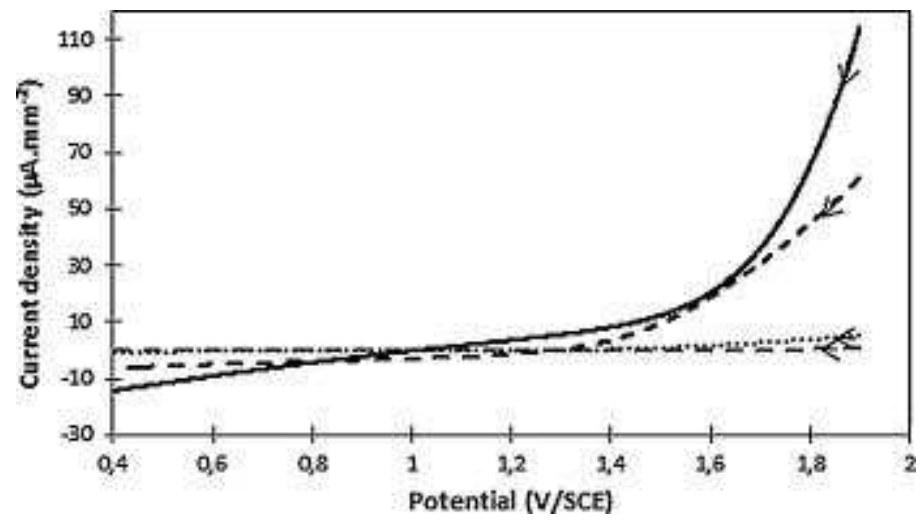

Figure 6. Oxygen evolution observed in phosphate buffer $(\mathrm{pH} 2.7)$ on plane graphite electrode (full line, $257 \mathrm{~mm}^{2}$ ) and on graphite felt for various current densities: considering the geometric surface (full dashes), the BET surface (empty dashes) and the electrochemical surface (dots). The scan direction was indicated by the arrow. Voltammogram recorded at 100 $\mathrm{mV} \mathrm{s}^{-1}$. 


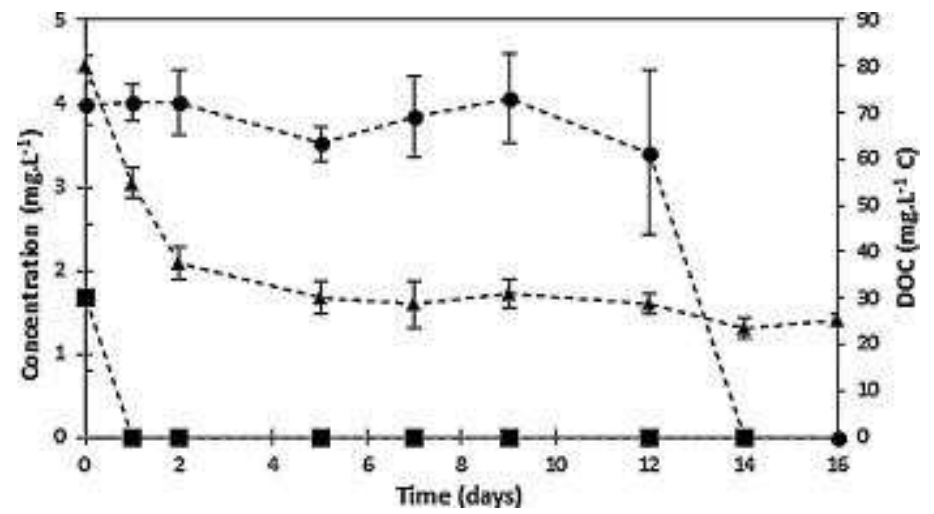

Figure 7. Time-courses of 2,4-D (circles), chlorohydroquinone (squares), and Dissolved Organic Carbon (triangles, right axis) concentrations during activated sludge culture on oxidized 2,4-D solutions (five times dilution of a $500 \mathrm{mg} \mathrm{L}^{-1} 2,4-\mathrm{D}$ solution electrolyzed at 1.6 V/SCE in $\left.0.1 \mathrm{M} \mathrm{Na}_{2} \mathrm{SO}_{4}\right)$. 